\title{
Redesigning the Circuits for Non-majors Course with the Addition of a Robotics Project
}

\section{Dr. Chad Eric Davis, University of Oklahoma}

Chad Davis received the B.S. in Mechanical Engineering (1994), the M.S. in Electrical Engineering (2000), and the Ph.D. in Engineering (2007) from the University of Oklahoma. Since 2008, he has been a member of the ECE faculty at the University of Oklahoma. Prior to joining the OU-ECE faculty he worked in industry at Uponor, McElroy Manufacturing, Lucent, Celestica, and Boeing. His work experience ranges from electromechanical system design to automation of manufacturing and test processes. His research at OU involves GPS Ground Based Augmentation Systems utilizing feedback control. Dr. Davis holds a dual discipline (electrical \& mechanical) professional engineering license in the state of Oklahoma.

\section{Dr. Pakize S. Pulat, University of Oklahoma}

Dr. Simin Pulat is the Associate Dean for Undegraduate Education in the College of Engineering and a Professor of Industrial and Systems Engineering at the University of Oklahoma. She holds a Ph.D. degree in Operations Research from the North Carolina State University.

Her research interests include broadening STEM education, recruitment and retention of diverse group of engineering students, transportation logistics, lean and six sigma applications. Dr. Pulat is a Fellow of the Institute of Industrial Engineers and a member of the American Society of Engineering Education. 


\section{Redesigning the Circuits for Non-majors Course with the Addition of a Robotics Project}

\section{Abstract:}

One of the most challenging tasks in engineering education is teaching courses to students that are outside their major area. The College of Engineering at the University of Oklahoma developed a unique curriculum for teaching circuits and other ECE concepts to non-ECE majors, where the traditional 18-week course is split into three one-credit hour 6-week modules. With this separation, different disciplines are able to build their curriculum to the needs of their students. The first two courses (ENGR 2431: DC Circuits and ENGR 2531: AC Circuits) primarily cover topics that non-majors are required to know for the FE exam. The final 6-week course (ENGR 3431: Electromechanical Systems) includes advanced topics not typically taught in an introductory circuits course, such as LabView programming, digital logic, computer communications, sensors, and motors. To provide a more practical and hands-on approach to the structure of ENGR 3431 a robotics project was implemented in the Spring 2011 semester. This paper focuses primarily on the implementation of this robotics project and uses student surveys and course evaluations to assess its effectiveness. Additionally, assessments of common multidisciplinary course problems of class size and student level disparity are also performed.

\section{Introduction:}

One of the most challenging tasks in engineering education is teaching courses to students that are outside their major area. Majors other than electrical and computer engineering (ECE) are not typically motivated about circuit theory and many educators have tried to address this challenge. ${ }^{1,2}$ With this lack of motivation in mind, the College of Engineering $(\mathrm{CoE})$ at the University of Oklahoma (OU) developed a unique curriculum for teaching circuits and other ECE concepts to non-ECE majors. One motivation common to non-ECE students in learning circuit theory is their desire to pass the Fundamentals of Engineering (FE) Exam. While attempting to capitalize on this source of motivation, an FE review book for ECE topics was utilized. $^{3}$ This book includes the additional ECE content for students taking the general engineering (renamed Other Disciplines in 2010) ${ }^{4}$ version of the FE exam. Topics such as 
sensors, instrumentation, and electrical machines were considered ideal additional content for the Chemical and Mechanical Engineering majors but not for other majors such as Industrial and Systems Engineering and Architectural Engineering. This led to the idea to split the Electrical Circuits course into three one credit-hour modules. The descriptions of these one credit-hour courses are shown in Table I. The course was taught in this new format for the first time at OU in the Fall 2009 semester.

\section{Table I - One Credit-Hour Circuit Course Modules}

\begin{tabular}{|c|c|c|}
\hline ENGR 2431: DC Circuits & ENGR 2531: AC Circuits & ENGR 3431: Electromechanical Systems \\
\hline $\begin{array}{l}\text { "Introduction to basic } \\
\text { principles of electrical } \\
\text { circuits. Topics include DC } \\
\text { circuit analysis, DC } \\
\text { transients, static electrical } \\
\text { fields, static magnetic } \\
\text { fields, capacitors, } \\
\text { inductors, and filters." }\end{array}$ & $\begin{array}{l}\text { "Introduction to intermediate } \\
\text { principles of electrical circuits. } \\
\text { Topics include basic complex } \\
\text { algebra, AC Circuit analysis, } \\
\text { resonance, AC transients, } \\
\text { transformers, and electronics } \\
\text { (diodes, operational } \\
\text { amplifiers)." }\end{array}$ & $\begin{array}{l}\text { "Introduction to basic principles of } \\
\text { electromechanical systems. Topics } \\
\text { include electric machines and motors, } \\
\text { physical principles of sensing and } \\
\text { actuation, types of sensors and actuators, } \\
\text { digital logic gates, signal conditioning, A/D } \\
\text { and D/A conversion, and interfacing and } \\
\text { communication protocols." }\end{array}$ \\
\hline \multicolumn{3}{|c|}{ Disciplines taking the individual course modules are as follows: } \\
\hline $\begin{array}{l}\text { Industrial, Architectural, } \\
\text { Chemical, Mechanical }\end{array}$ & Mechanical & $\begin{array}{l}\text { Chemical, Mechanical (Only ENGR } 2431 \\
\text { is a prerequisite for ENGR 3431) }\end{array}$ \\
\hline \multicolumn{3}{|c|}{ These three courses are taught sequentially in the following order: } \\
\hline First $3^{\text {rd }}$ of semester & Middle $3^{\text {rd }}$ of semester & Last $3^{\text {rd }}$ of semester \\
\hline
\end{tabular}

The first course in the sequence, ENGR 2431: DC Circuits, includes the majority of the topics that are on the morning session of the FE Exam and considered by the National Council of Examiners for Engineering and Surveying (NCEES) to be important for all engineering disciplines. FE exam-style questions are given on quizzes and exams so the students can prepare for the FE in this course while learning the subject matter. Having the majority of the electrical FE topics in this course allows some disciplines to only take this course and use the other two 
credit hours for different subjects that are more important to their engineering discipline. Industrial and Systems Engineers (ISE) replace ENGR 2531 with ENGR 2461 (a one credit hour thermodynamics course) and ENGR 3431 with ENGR 3441 (a one credit hour fluid mechanics course). Architectural Engineers (AE) only take ENGR 3401 (a one credit hour engineering economics course) along with the ENGR 2431 DC circuit's course. These one credit-hour module courses are an excellent way for departments to add more discipline-specific content into the program while maintaining a well-rounded engineering education.

The second course in the sequence, ENGR 2531: AC Circuits, includes AC circuit fundamentals with the inclusion of phasors and complex algebra. These topics are included on the morning session of the FE exam for all disciplines. By emphasizing the FE exam in ENGR 2431 and ENGR 2531 and using a FE Review book ${ }^{3}$ for the textbook in the courses, the students are given a good reason to be motivated for the courses. One additional topic in ENGR 2531 is an introduction to electronics. Included in this portion of the course is an overview of diodes, transformers, and operational amplifiers. This brief electronics background is a desirable feature of the course for mechanical engineering students. The Chemical Engineers (ChemE) take ENGR 2431 and ENGR 3431, but replace ENGR 2531 with ENGR 2411 (a one credit hour applied engineering statics course).

The third course in the sequence, ENGR 3431: Electromechanical Systems, includes a variety of topics that are only included in either the electrical engineering or "other discipline" FE exam. Since these topics are not on the FE exam for the engineering disciplines of the students in ENGR 3431, the motivational technique of the first two classes is no longer an option. The numerous additional topics that need to be covered in ENGR 3431 make it an ideal setting for a hands-on robotics project. In this way many topics can be discussed in a short amount of time and the students can learn how they all work together. Since most of the additional topics are far outside their field of study, using only a lecture-based approach to the course was found to be less effective in motivating the students than applying the knowledge in a practical hands-on robotics project. Data supporting this claim are presented in later sections. The rest of this paper will focus on ENGR 3431 and the effectiveness of adding a robotics project in this course. The primary objectives of the ENGR 3431 course are to give students an understanding of many 
advanced concepts in ECE and empower them to be able to apply the knowledge in their future careers.

\section{ENGR 3431 Challenges}

We first discuss the challenges associated with the delivery of ENGR 3431 and then explain how incorporating a robotic project into the course addressed these challenges. The primary challenge was that most of the ChemE students take this course during their spring semester of their senior year and the Mechanical Engineers (MEs) usually take it in the spring semester of their sophomore year.

\section{A. Class Size Mismatch in the Fall and Spring Semesters}

The first issue that arose from this scheduling dilemma was an extreme mismatch in the number of students that enroll in ENGR 3431 in the fall and spring semesters. Over the last three fall semesters the course has averaged less than 20 students per semester, while in the spring it has averaged over 120 students per semester. The large spring enrollment requires the course to be taught in a large lecture hall. This venue makes demonstrations in the course impractical. For a course like ENGR 3431 with many topics, hands-on demonstrations would be an ideal teaching tool. During the first offering of ENGR 3431 in its redesigned format, demonstrations were effectively used and the feedback from the 18 students in the course was very positive. When offered in the spring 2010 with 120 students it was found to be ineffective. Student feedback regarding the course effectiveness was significantly different between spring and fall semester offerings.

Figure 1 shows distribution of scores on the course effectiveness for the semesters ENGR 3431 was taught prior to the robotics project being implemented into the course (Fall 2009, and Fall 2010 combined) and Spring 2010. In the evaluation form, the students were asked to respond on a scale from 1 to 5 to the statement "Overall, this course was". There were 67 responses in the evaluations in Spring 2010 with an average response of 2.7. There were 22 total responses in the evaluations in Fall 2009 and 2010 with an average response of 3.9. Figure 1 shows the 
statistical mode was " 3 " for the students in Spring 2010 and "5" for the students in the fall semesters. A score of 5 is described as the most favorable score in the evaluation form.

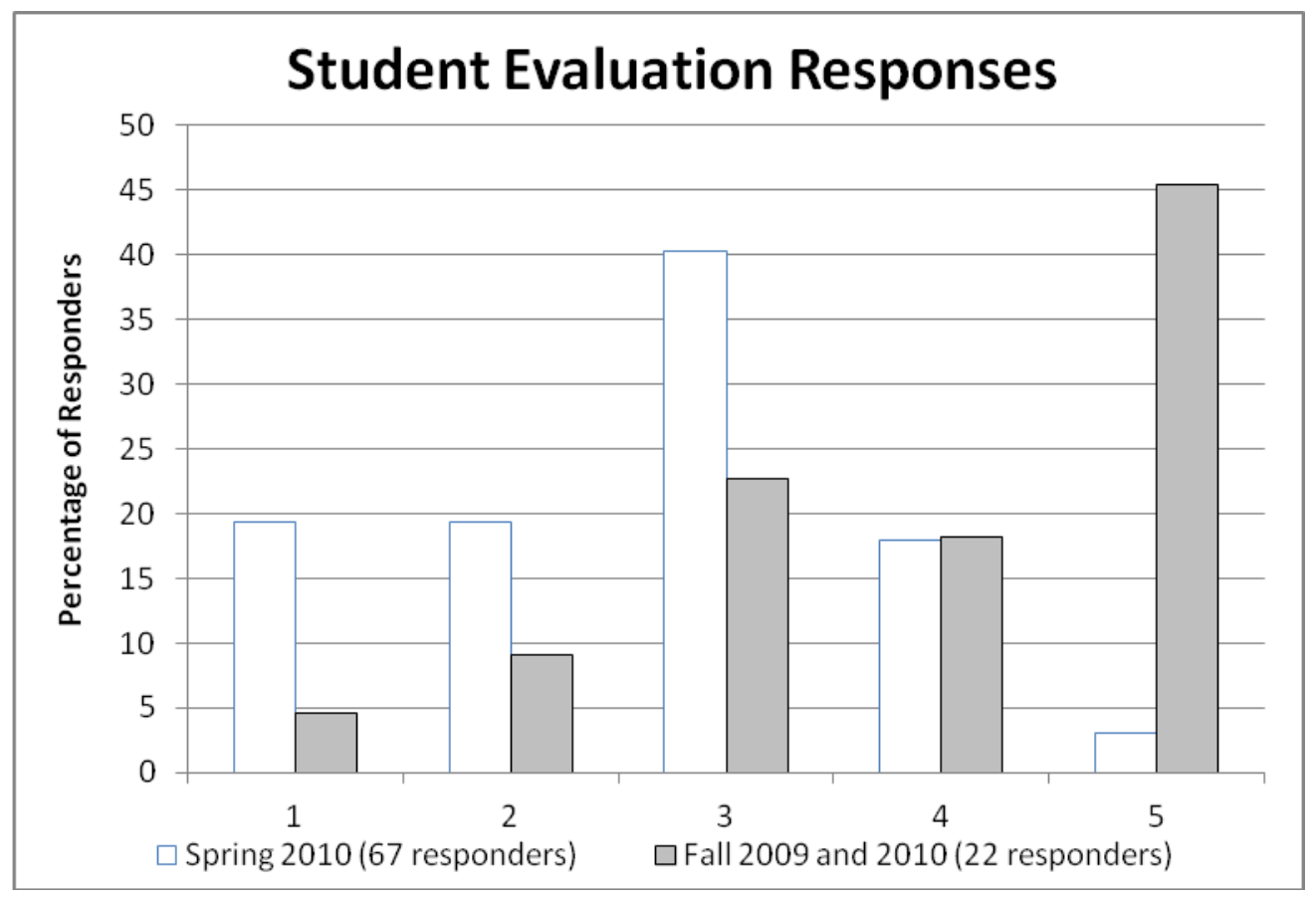

Fig. 1: ENGR 3431 evaluation response on Course Effectiveness

\section{B. Student level mismatch between ChemE and ME students}

The second issue that arose was an extreme mismatch in the level of students. The ENGR 3431 students filled out an anonymous survey in the Spring 2012 semester. The following section of the survey shows the questions that were asked to determine the level of student for each of the majors:

1. What is your engineering major? Mechanical Chemical Aerospace Other:

2. What year are you? List the year based on your progress towards your degree, not by hours. Example: 1.5 would be the $2^{\text {nd }}$ semester of your freshman year; 4.5 would be your last semester.

\begin{tabular}{|lllllll|}
\hline 1.5 & 2 & 2.5 & 3 & 3.5 & 4 & 4.5 \\
\hline
\end{tabular}


Additional, survey responses are discussed in later sections of the paper. Figure 2 shows that most ChemE students are second semester seniors (4.5) and most of the ME students are second semester sophomores (2.5).

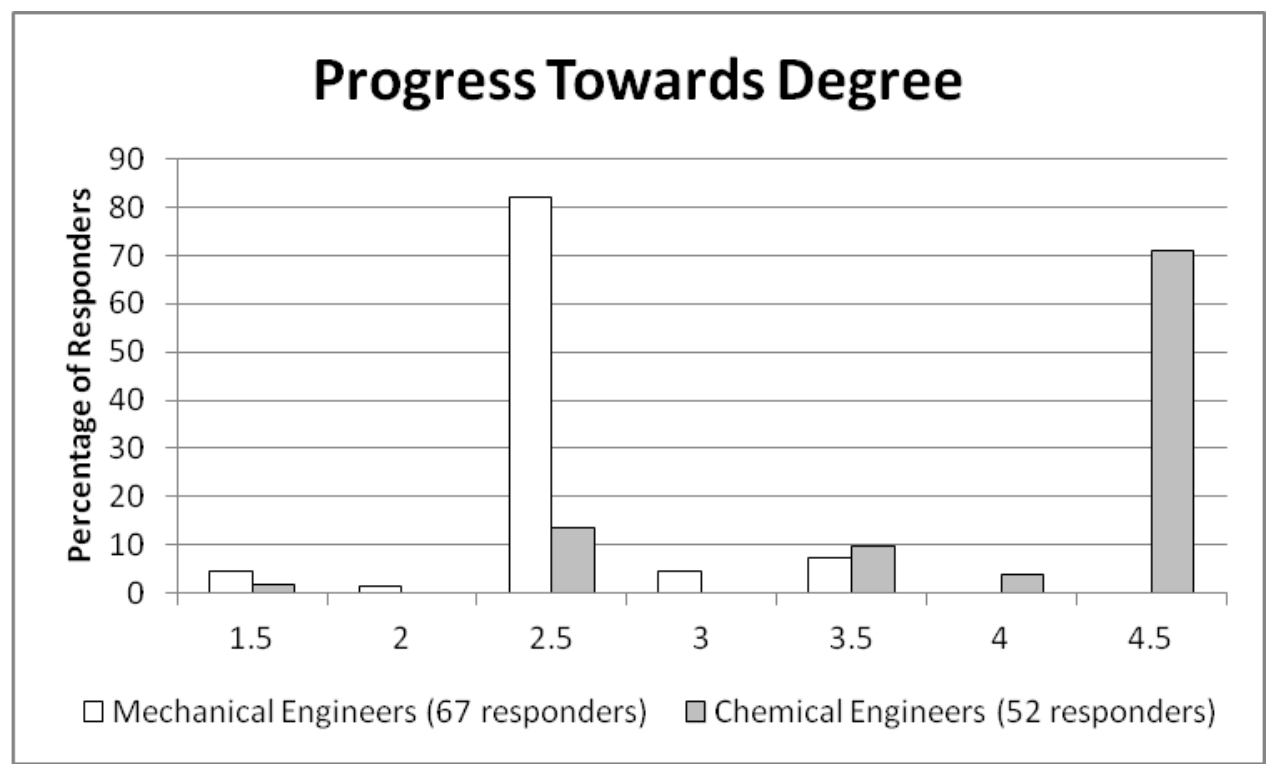

Fig. 2: Spring 2012 Survey: progress towards degree. $1.5=2^{\text {nd }}$ semester freshman.

From experience with this course, the sophomore level ME students tend to embrace the opportunity to do a robot competition, but the ChemE students are more resistant because seniors don't feel they have time for an additional project as they are busy working on capstone course requirements and making preparations to graduate.

\section{Implementation of a Robotics Project}

The decision to incorporate a robotics project into the ENGR 3431 course came after the poor course effectiveness evaluations following the Spring 2010 semester. After the first teaching of ENGR 3431 in the Fall 2009 semester, a lecture-based approach with several hands-on demonstrations seemed to work well for the course that included only 18 students. The evaluations were very favorable and the students appeared to be motivated to learn the advanced ECE topics presented in the course. The evaluation responses to the question related to the overall effectiveness of the course were much higher than other courses in the $\mathrm{CoE}$ at $\mathrm{OU}$. 
When moving to a large lecture hall with 122 students in the Spring 2010 semester, the approach of the course did not translate well because it was more difficult to effectively use hands-on demonstrations. While researching other pedagogical approaches ${ }^{1,2,13,14}$ to circuits for nonmajors courses, two common themes emerged. First, incorporating hands-on experimental learning opportunities is a best practice for this type of course. Second, it is desirable to make the courses with electrical subject matter as practical and relevant as possible. Since the infrastructure for a lab-based course was not available, a method to bring a hands-on element into the large lecture hall was desired. After discussing the situation with another professor who implemented a robotics project into a freshman orientation course ${ }^{5}$ and seeing others implement robotics into more advanced courses ${ }^{7,10,12}$, a decision was made to implement a robotics project into ENGR 3431 before the Spring 2011 semester.

The robotics project in the Freshman Engineering Orientation course ${ }^{5}$ focused on a fun activity that would allow the students to work on a team, but didn't include advanced technical requirements that were desired in the ENGR 3431 course. The first challenge was selecting a robotics platform for ENGR 3431. It needed to be simple enough for the students to complete in two to three weeks, but complex enough to cover the theory of many of the required elements in the course. The first platform consideration was using a modified remote controlled vehicle that has been successfully implemented in past outreach events ${ }^{6}$ and ECE courses. This platform could be used to cover sensors and digital logic, but would be more difficult to cover some of the more advanced topics such as $\mathrm{A}$ to $\mathrm{D}$ conversion and computer interfacing. The LEGO Mindstorm platform used in the previously mentioned freshman orientation course was another potential solution. The problem with this platform was the LEGO software is not a tool that will be useful for the students in industry and could not be leveraged to teach other requirements of the ENGR 3431 course. However, the LEGO Mindstorm can be programmed in LabView, which is a valuable tool used in industry by many engineering disciplines. This was an ideal solution because LabView could also be used to teach the theory behind many of the other topics in the course. Erwin et al. "found that the graphical format of LabView allows us to concentrate much more on the science or engineering being taught and a lot less on checking syntax of the programming." 7 
To further tie the theory to the robotics project, a report was incorporated that required the students to perform motor calculations using the LEGO NXT speed versus torque motor curves and complete a detailed report describing the theory of the sensors used in with the NXT robot. The sensors used in the robot project are acoustic sensors, light sensors, ultrasonic sensors, pressure sensors, and encoders. Demonstrations of a variety of sensors are also provided in class using data acquisition hardware and LabView software. One example that is always included is using an infrared LED and a phototransistor to show how the light sensors work internally. For the motor calculation section of the report, the following experimentally-determined motor specifications are provided: stall torque, no load speed, stall current, and no load current. Using these parameters the students are required to create a speed versus torque, current versus torque, power versus torque, and efficiency versus torque curves. During the lectures other types of motors are examined, including motors with internal gearing. The students learn to calculate the operating speed and torque values at their operating load as well as the electrical power, mechanical power, and efficiency. Performing detailed motor calculations is a great way to provide a practical element to the course and something that will be useful to many of the students in their careers. A similar methodology was used in an introductory ECE class for nonmajors at Worcester Polytechnic Institute. ${ }^{14}$ This paper ${ }^{14}$ shows detailed calculations and figures of the motor theory that is taught in ENGR 3431.

Next, the type of project that would motivate students to participate needed to be determined. With prior experience in FIRST robotics, we felt that it would be a good model for the robot project portion of this course. FIRST is excellent at motivating students to aspire to do something that is outside their area of expertise. Every year, thousands of excited students meet on the same day to witness the unveiling of the new competition for the year. ${ }^{8}$ Following this kick-off meeting the teams have around six weeks to complete their robot. During this 6-week period the students must rely on teamwork and mentor help to accomplish something that seems overwhelming at the onset. At the completion of the build period, the teams battle in a competition that has an atmosphere similar to an athletic championship contest.

To model the ENGR 3431 project after FIRST, the students are put into teams, given robot kits (as described in the next section), and challenged with the details of the robotics competition at 
the beginning of the semester. With the short timeline of the course and the capstone conflicts for chemical engineering students, the competition is held within three weeks after the kits are distributed. Over the build period, lectures tie the theory of the course to the robot project.

One challenge with this model is that most of the students don't know how to program in LabView so it is a daunting task for the students at the beginning. To provide enough LabView training for them to be successful, the students are directed to online tutorials and given a LabView state machine assignment in the first week of the course. All robots are required to be programmed using a LabView state machine architecture. This requirement eliminates most of the potential for the students to copy code from online sources and allows them to learn a valuable tool for implementing decision-making algorithms. The state machine is one of the most useful architectures available to LabView programmers. According to National Instruments, the creator of LabView, "The State Machine is one of the fundamental architectures LabView developers frequently use to build applications quickly. State Machine architecture can be used to implement complex decision-making algorithms represented by state diagrams or flow charts." ${ }^{9}$ Requiring the state-machine software architecture in LabView raises the technical level well beyond that of the freshman orientation project that uses the LEGO software package. It also allows them to perform far more complicated tasks and gives them the opportunity to implement a state diagram into software. The state diagram is a multidisciplinary engineering tool that the students have likely used in previous courses or will use in the future. Figure 3 shows a screenshot of a student group's LabView code for the Spring 2011 final competition. While only one state of the program is shown, several other states are needed to be able to successfully complete the competition. Many of the blocks shown in figure 3 correspond to topics in the course. Some of these are digital logic gates, threshold elements, sensors, motors, speed settings, and the ports used for computer communication. 


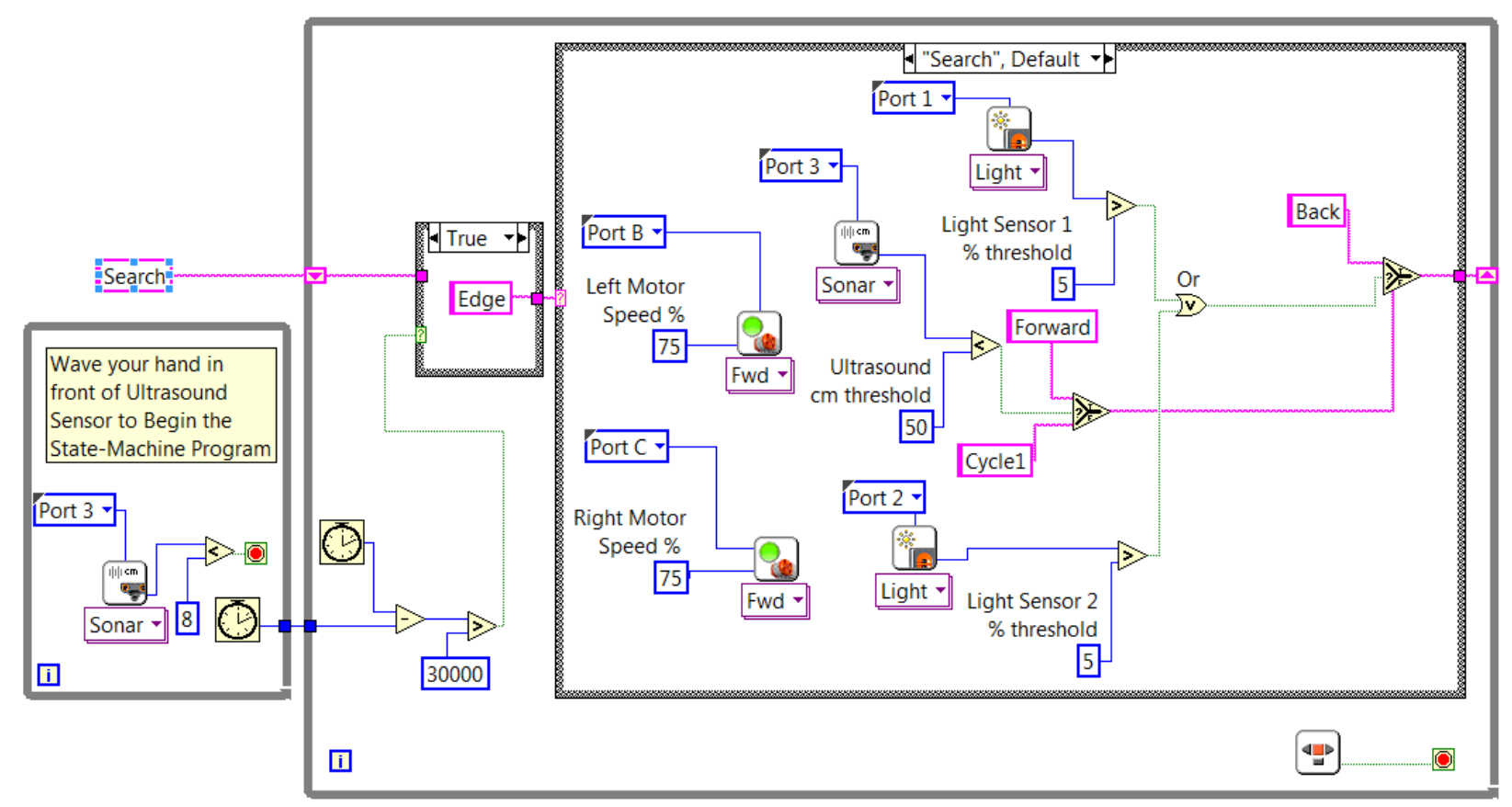

Fig. 3: Example of State-Machine Programming using LabView and the NXT Module

\section{LEGO Mindstorm NXT Platform Description}

For the ideas discussed in this paper to be implemented by others, the kit of parts the students are given to complete their robotics project will first be described. All parts are put in a small lightweight toolbox that the students can easily carry around with them. The LEGO Mindstorm kit (Part \# 8547) includes 1 NXT processor, a battery with charger, a USB cable to connect the NXT to the computer, 3 motors with internal encoders, 2 Light sensors, 2 pressure sensors, 1 sound sensor, and 1 ultrasound sensor. Many additional sensors are also available from LEGO. The LEGO Mindstorm kit also includes an adequate supply of LEGO pieces. Additionally, an LED flashlight is purchased separately and included in the toolbox. The light sensors can be used in reflective mode with an internal LED source or in ambient mode, where a flashlight or other form of external lighting can be used to control the robot. The students are then required to install LabView and the NXT Robotics module on their laptops, both of which can be downloaded from NI.com. More advanced projects can also be implemented with this platform. ${ }^{10}$ For example, we used these NXT kits in the Fall 2012 semester in an upper division elective course to do a more technically advanced project. This project required students to implement PID control algorithms in LabView to create synchronized NXT robots. The NXT 
Mindstorm platform has proven to be a versatile platform. They have been used at _ in numerous ways and for varying student levels. The Mindstorm has been used with the LEGO NXT software for hands-on activities for high school outreach events and freshman orientation projects. Using the NXT platform with LabView has allowed it to be used for the ENGR 3431 course, an upper division elective course, Robotics Club events, and even LabView training seminars for graduate students.

\section{Description of the Robot Competition}

A FIRST Robotics concept that is incorporated into the ENGR 3431 project is “coopertition " ". 11 This term is a combination of cooperation and competition. When designing a competition with over 120 students that includes brand new topics, it is important to create an environment where students have an incentive to cooperate with each other. This is done by incorporating a system where two teams are reliant on each other to win the competition. This reliance will be explained in the descriptions of the competitions.

\section{A. Spring 2011 Competition}

Qualification Round: Each team selected another team to be their alliance partner. Both team's robots compete together with their alliance partner during the qualification round and the highest scoring alliances advanced to the Elimination Round. The primary goal of this round was to push blocks out of a black ring with a 2" white ring around the outside edge. A point was awarded for each block that was pushed out. Other tasks were included to obtain additional points and deductions were given for a variety of penalties.

Elimination Round: The teams that advanced from the qualification round were seeded based on their total points. A single elimination bracket style tournament determined the winner. The point system was similar to that of the qualification round. The main difference was that there were no alliances so all teams competed against each other. 
Evaluation: After the semester, the pros and cons of this competition were studied. The following are some of the positive comments listed in the evaluations that supported the idea of continuing the competition in the course:

- "Really enjoyed the class. The projects were fun and related to the class."

- "I enjoyed the competitions and building the robots immensely and learning a new program..."

- "The projects to build and program robots to do certain tasks were amazing. A lot of fun and great learning tools."

The following are some of the negative comments listed in the evaluations that coincide with changes that were made prior to the Spring 2012 semester.

- "Most of the chemical engineers in your class are seniors, and trying to work on Capstone along with this class"

One thing to note is that during the Spring 2011 competition the final project competition occurred in the second to last class period. This was corrected prior to the Spring 2012 semester so the project is over before the last two weeks of the course.

- "In the group project only one person was doing the programming so I felt like I missed out on that aspect of the course."

Due to a limited amount of equipment the group sizes were too large for everyone to be involved in the LabView programming portion of the robot project in the Spring 2011 semester. However, every student was required to complete a homework assignment where they wrote a unique LabView state-machine program that was modified from an online tutorial. They were also required to make screenshots of every state (one state is shown in figure 3) and explain the details of what the program is doing. In order to get more students involved in the programming portion of the robot project, additional equipment was purchased prior to the Spring 2012 semester to make group sizes smaller. Additionally, prior to the Spring 2012 project each robot kit was given to two subgroups that each had to have an independent program. These changes forced everyone to contribute in the programming of the robot.

B. Spring 2012 Competition 
Taking into consideration the comments and observation from the Spring 2011 semester a new competition was created. This competition had two subgroups that shared a robot, but had independent LabView programs that were executed during the competition.

Phase 1 of the competition required the robot to autonomously navigate around ring with an electrical tape oval on a white background. The robot started next to a stationary object and traveled around the oval until it reaches the other side of the object. The robot then turned around and traveled the other direction until it touched the object on the other side.

Phase 2 After the second time the battery was touched, the robot had to locate balls that were placed outside the track and push them to the other side of the ring. To increase the level of coopertition $^{\circledR}$ the scoring included both the subgroups. A group's combined score was equal to $(2 \mathrm{X}+\mathrm{Y}) / 3$ where $\mathrm{X}$ is the lowest (or fastest) time of the two subgroups and $\mathrm{Y}$ is the slowest.

Evaluation: The Spring 2012 competition solved the unintended negative consequences associated with the Spring 2011 version. First, there was only one competition in spring 2012 instead of two. Having two competitions in spring 2011 turned out to be a little too much work for the students. Second, the competition occurred two weeks earlier in spring 2012 so it didn't compete with capstone final projects or final exam preparation. Third, the additional equipment purchased prior to the spring 2012 allowed everyone to contribute to the programming of the robots. Finally, the project report requirements were also modified in Spring 2012. Each student was required to turn in a report and a template was provided to guide the students and reduce the ambiguity. Motor calculations were required on the report along with a more detailed theoretical sensor discussion. Those additions served to better tie in the theory of the course to the competition.

\section{Results}

Evaluations results were the first method used to assess the effectiveness of the robotic competition in ENGR 3431. Figure 4 shows evaluation responses for Spring 2010, 2011, and 2012. The numbers in the parenthesis show the mean response. With no competition in Spring 
2010, the data shows that the students felt the course was far less effective. The data also shows that the percentage of students that responded negatively to this statement (responded 1 or 2) was 39\%, 19\%, and 18\% in Spring 2010, 2011, and 2012, respectively.

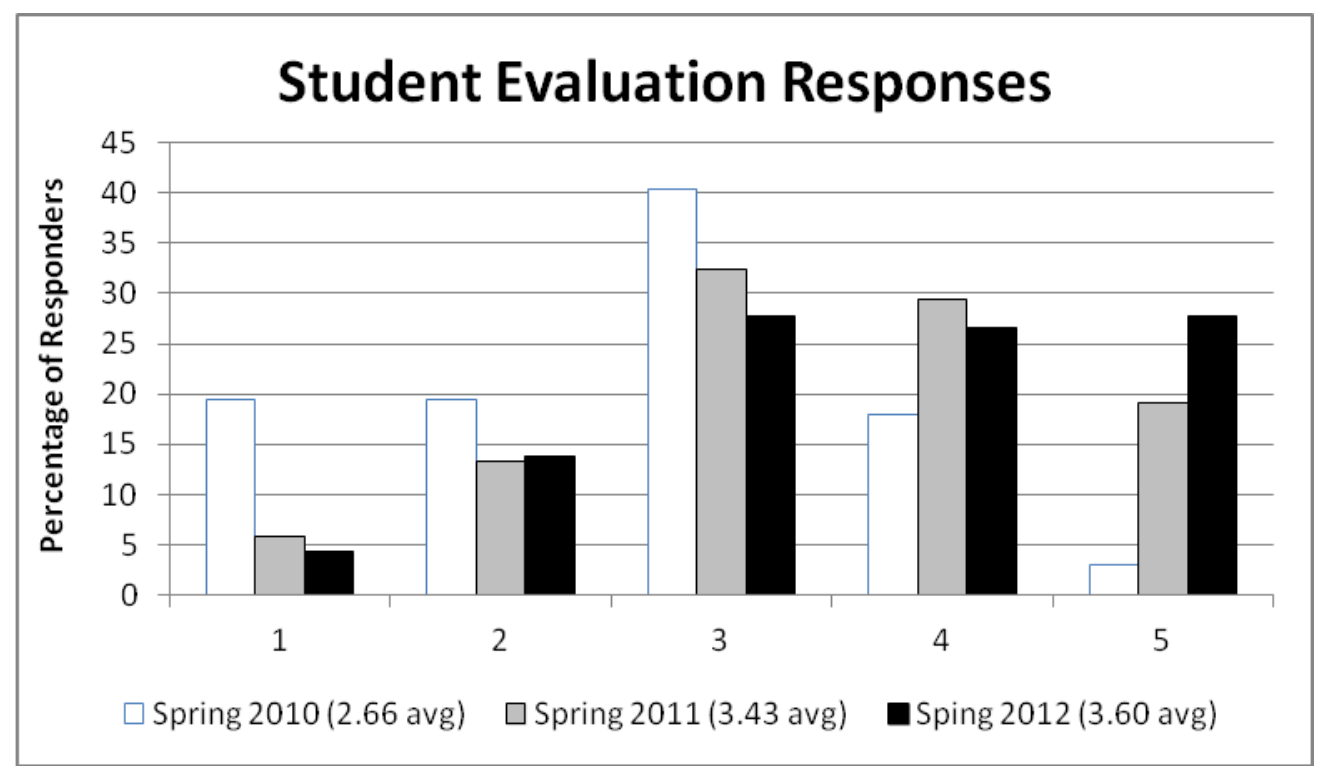

Fig. 4: ENGR 3431 evaluation on course effectiveness

In addition to the course evaluations, an anonymous survey was taken in the Spring 2012 semester. The results of the first two questions are displayed in Figure 2. For questions 3 through 10 the responses were limited to $1,2,3$, or 4 . The students were instructed in the survey that " 1 equates to the most negative response and 4 equates to the most positive response". In order to prevent the students from a neutral response, only 4 choices were listed. This will allow a threshold to be applied to the data and responses 1 and 2 can be associative with negative responses and responses 3 and 4 can be associated with positive responses. The survey questions related to the robotics project are shown below:

3. How much were you in involved with the construction of the robot?

4. How much were you involved with the programming of the robot?

5. The robot project increased my ability to work on a team?

6. The robot project increased my understanding of the intelligent design involved in robotics?

7. The robot project increased my understanding of how sensors work?

8. The robot project increased my understanding of how motors work? 
9. The robot project increased my understanding of programming in robotics?

10. The robot project added value to this class (in other words, it was a good idea)?

The final question, \#11, designed to determine how much the students felt they learned from the project. Again, there is no neutral response option. Some students circled the middle two options and stated it was somewhere in between. In these cases the responses were not used in the final statistical analysis.

11. Compare how much you learned on this robot project to others you have done at OU?

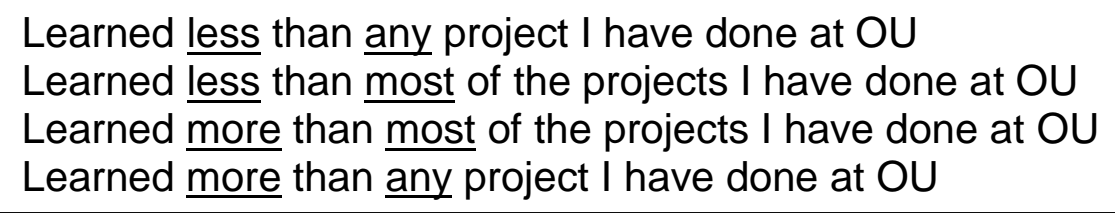

The results from questions 3 through 11 are shown in Table II. Question 11 is converted to a 1 to 4 scale, where 1 is the response "Learned less than any project I have done at OU." The survey shows that the students responded positively to all areas that were intended in the course.

Table II - Survey Results

\begin{tabular}{|c|c|c|c|c|c|c|}
\hline & & 1 & 2 & 3 & 4 & mean \\
\hline \multirow{2}{*}{ 3) ... involved with the construction... } & $\mathrm{C}$ & 7 & 13 & 13 & 19 & 2.85 \\
\hline & M & 7 & 12 & 19 & 29 & 3.04 \\
\hline (67.2\% responded positively) $(* 70.7 \%)$ & $\mathrm{T}$ & 14 & 25 & 32 & 48 & 2.96 \\
\hline \multirow[t]{2}{*}{ 4) ...involved with the programming... } & $\mathrm{C}$ & 5 & 8 & 12 & 27 & 3.17 \\
\hline & M & 9 & 17 & 11 & 30 & 2.93 \\
\hline (67.2\% responded positively) ( $* 100 \%)$ & $\mathrm{T}$ & 14 & 25 & 23 & 57 & 3.03 \\
\hline \multirow[t]{2}{*}{ 5) ... increased my ability to work on a team } & $\mathrm{C}$ & 6 & 10 & 17 & 19 & 2.94 \\
\hline & M & 4 & 19 & 20 & 21 & 2.90 \\
\hline (66.4\% responded positively) $(* 73.1 \%)$ & $\mathrm{T}$ & 10 & 29 & 37 & 40 & 2.92 \\
\hline \multirow[t]{2}{*}{ 6) ...intelligent design involved in robotics } & $\mathrm{C}$ & 2 & 2 & 20 & 28 & 3.42 \\
\hline & M & 2 & 10 & 19 & 36 & 3.33 \\
\hline ( $86.6 \%$ responded positively) $(* 88.8 \%$ ) & $\mathrm{T}$ & 4 & 12 & 39 & 64 & 3.37 \\
\hline \multirow[t]{2}{*}{ 7) ...understanding of how sensors work } & $\mathrm{C}$ & 0 & 7 & 16 & 28 & 3.41 \\
\hline & M & 2 & 9 & 25 & 31 & 3.27 \\
\hline (84.7\% responded positively) $(* 85 \%)$ & $\mathrm{T}$ & 2 & 16 & 41 & 59 & 3.33 \\
\hline \multirow[t]{2}{*}{ 8) ... understanding of how motors work } & $\mathrm{C}$ & 4 & 12 & 16 & 20 & 3.00 \\
\hline & M & 4 & 21 & 17 & 25 & 2.94 \\
\hline (65.5\% responded positively) $(* 67.5 \%)$ & $\mathrm{T}$ & 8 & 330 & 33 & 45 & 2.97 \\
\hline \multirow[t]{2}{*}{ 9) ...of programming in robotics } & $\mathrm{C}$ & 2 & 1 & 15 & 34 & 3.56 \\
\hline & M & 6 & 6 & 22 & 33 & 3.22 \\
\hline$(87.4 \%$ responded positively) $(* 90 \%)$ & $\mathrm{T}$ & 8 & 7 & 37 & 67 & 3.37 \\
\hline 10) The robot project added value to class & $\mathrm{C}$ & 1 & 7 & 16 & 28 & 3.47 \\
\hline
\end{tabular}




\begin{tabular}{crrrrrr} 
& M & 2 & 5 & 14 & 46 & 3.55 \\
\hline (87.4 \% responded positively) $(* \mathbf{9 0 \% )}$ & $\mathrm{T}$ & 3 & 12 & 30 & 74 & 3.47 \\
\hline 11) Compare how much you learned ... & $\mathrm{C}$ & 0 & 9 & 35 & 5 & 2.90 \\
& $\mathrm{M}$ & 0 & 8 & 44 & 14 & 3.10 \\
\hline $\mathbf{8 5 . 2 \%}$ responded positively) $(* \mathbf{8 9 . 7 \% )}$ & $\mathrm{T}$ & 0 & 17 & 79 & 19 & 3.01 \\
\hline
\end{tabular}

Notes: $C=$ Chemical, $M=$ Mechanical, $T=$ Total. ${ }^{*}$ Subset of the 80 positive responders to question 4

The decision to do only one survey instead of a pre-course and post-course survey was due to the fact that this course is outside the student's field of study and almost none of the students were knowledgeable about these topics prior to the course. For this reason, a pre-course and postcourse survey method would have inflated the results. The survey was given at the end of the course after the students have learned more about the topics from the lectures and the text. In this way the students had an understanding of the topics and responded to whether they felt the project increased their learning.

The evaluation results in Figure 4 served to show the students perceived value of the course before and after the robot competition was included. Since increasing the student's motivation is one of the primary goals of this study, the student's perceived value of the course is a very appropriate assessment metric. It was very encouraging to observe that $17 \%(19 / 115)$ of the students responded to survey item 11 that they learned more on this project than any other project they have done at OU, while zero students responded that they learned less on this project than any other project they have done at OU. When separating the $67.2 \%(80 / 119)$ of students that responded either 3 or 4 to the question regarding involvement in the programming of the robot, the results for every survey item improved. This improvement is shown in Table II and indicated with an $*$. This is evidence that getting the students involved in the programming aspects of the project is critical to its effectiveness. Adding in the state machine report requirements for every student likely added to the knowledge that the students gained in the project. Evidence of this statement is that while only $67.2 \%$ responded positively to their involvement in the programming of the robot, $87.4 \%$ responded positively to the statement: "the robot project increased my understanding of programming in robotics".

VII. Conclusions 
This paper shows several findings that can assist ECE faculty with the difficult task of teaching ECE topics to non-ECE students. Separating the traditional circuits for non-majors course into one-credit hour modules allows the different disciplines to build their curriculum to the needs of their students. It also allows new topics that are usually not taught in a circuit's course to be covered. With this model, the addition of a robotics project was found to be feasible and effective. This is true even when the class size is large and the classroom is not ideal. This paper showed data that strongly supports the notion that a large class size reduces the effectiveness of a course. It is of primary importance that all engineering departments strive to minimize class size and keep them balanced between semesters. This paper also provided a methodology for incorporating the LEGO Mindstorm robotics platform into an engineering course. By modeling a robotics competition after FIRST Robotics principles and the blueprint presented in this paper, desirable results can be expected. The evaluation and survey data presented in this paper show positive signs that integrating a robotics project into ENGR 3431 was a successful learning tool. Additional data needs to be obtained to further quantify how successful this approach is in teaching a circuits for non-majors course.

\section{References}

1. A. Oliveira, "Challenges of Teaching Electrical Engineering Classes to Nonmajors," ASEE Annual Conference \& Exposition Proceedings, AC 2009-58, 2009.

2. H. Alnajjar and L. Godbout, "Web-Based Circuit Animator to Aid in Teaching Circuit Theory," ASEE Annual Conference \& Exposition Proceedings, Session 1532, 2003.

3. M. Sveum, ““'FE Exam Review: Electrical and Computer Engineering”. Belmont, CA: PPI, 2006.

4. "NCEES renames FE exam module". ncees.org http://www.ncees.org/About_NCEES/News/News_Pages/FE_Other_Disciplines_module.php Accessed: 5/17/2012.

5. C. Davis, M. Yeary, and J. Sluss, "Reversing the Trend of Engineering Enrollment Declines with Innovative Outreach, Recruiting, and Retention Programs" IEEE Trans. Educ., DOI 10.1109/TE.2011.2157921, accepted and to appear 2012.

6. C. Davis, M. Yeary, and J. Sluss, "Results and best practices of a two year study on recruiting programs to boost ECE undergraduate enrollment," ASEE Annual Conference and Exposition, paper AC 2011-1539, pp. 1-17. June 2011.

7. Erwin, B. Cyr, M.; Rogers, C., 2000, "LEGO engineer and RoboLab: teaching engineering with LabView from kindergarten to graduate school," Int. Journal of Engineering Education, v. 16, n. 3, 2000, pg. 192.

8. C. Davis, "Work in Progress - FIRST Robotics Competition from the Perspective of a First Time Mentor" 39th ASEE/IEEE Frontiers in Education Conference, Oct. 2009.

9. “Application Design Patterns: State Machines", ni.com. http://www.ni.com/white-paper/3024/en Accessed: 5/17/2012.

10. Gómez-de-Gabriel, J.M., Mandow, A., Fernández-Lozano, J., García-Cerezo, A.J. (2011) "Using LEGO NXT Mobile Robots With LabView for Undergraduate Courses on Mechatronics," IEEE Transactions on Education, vol.54, no.1, pp.41-47, Feb. 2011. 
11. "Gracious Professionalism", usfirst.org. http://www.usfirst.org/aboutus/gracious-professionalism Accessed: $5 / 17 / 2012$.

12. Williams, A. B., 2003, "The qualitative impact of using LEGO MINDSTORMS robots to teach computer engineering," IEEE Transactions on Education, v. 46, n. 1, Feb. 2003, p. 206.

13. J. Hatfield, D. Scott, D. Szmyd, "A freshman electrical engineering course and laboratory for all engineering majors," ASEE- IEEE Frontier in Education Conference Proceedings, pp. 4c2.1-4c2.4, Vol.2, 1995.

14. Makarov, S., Ludwig, R., Win, K.M., "Basic Class Materials and Laboratory Projects With DC Motors in an Introductory Undergraduate ECE Class for Non-Majors," ASEE Annual Conference \& Exposition Proceedings, AC 2011-1184, 2011. 